\title{
Pyomyoma in A Patient with A History of Xanthogranulomatous Pyelonephritis
}

\author{
Deus Botti C*, Vilà Famada A, LleberiaJuanos J, Pubill Soler J, Mestre Costa M and García-Chamon, RB \\ Corporación Sanitaria Parc Taulí, Hospital Parc Taulí de Sabadell, Spain
}

Submission: February 08, 2019; Published: February 21, 2019

*Corresponding author: Deus Botti C, Corporación Sanitaria Parc Taulí, Hospital Parc Taulí de Sabadell, Spain

\begin{abstract}
It is common to find fibroids with signs of degeneration in our usual clinical practice, but their infection results in a very low incidence clinical picture. Probably for this reason, there is no protocolized treatment in the literature for the clinical management of 'pyomyoma'. We introduce a clinical case of a patient with fever and pain in the right iliac fossa who repeatedly consulted the emergency department in our center. As pathologic background, the previous month she presented a nephrectomy caused by a xanthogranulomatous pyelonephritis. A Computarized Tomography study was performed, with witch intramural myoma with degenerative characteristics was visualized without being able to rule out a pyomyoma. The clinical evolution of the patient led to the assessment of the myoma by guided puncture, what allowed the diagnostic orientation. Finally, surgery was decided, performing an abdominal hysterectomy that confirmed the diagnosis..
\end{abstract}

Keywords: Pyomyoma; Myoma degeneration; Infection; Abscessification

Abbreviatations: CT: Computerized Tomography; PAAF: Fine-Needle Puncture Aspiration; IUD: Intra-Uterine Dispositive; MRI: Magnetic Ressonance Imaging

\section{Introduction}

Uterine myoma is the most frequent gynecological benignous tumour, formed by myometral cells inside a capsule of fibroid tissue. It is a hormone-dependant tumour so can grow in situations of high hormonal stimulation like, for example, gestation [1,2]. It can also present, structural disturbances like hialin degeneration (fibrosis increasement), calcification or red degeneration (necrosis and haemorrhage) [3,4].

\section{Clinical Case}

Patient of 48 years old, carrier of IUD Mirena ${ }^{\circledR}$, with previous history of nephrectomy due to diagnosis of xanthogranulomatous pyelonephritis by Proteus mirabilis and correct postoperative evolution, consulted the emergency room due to pain in the right iliac fossa with fever and vomits, which started around a month and a half after the surgery. Analytically presented $24.84 \times 10^{\wedge} 9$ Leucocytes/L (90.1\% of Neutrophils, $5.8 \%$ of lymphocytes), C-reactive protein concentration of $34.50 \mathrm{mg} / \mathrm{dL}$, Hemoglobin concentration of $10.1 \mathrm{~g} / \mathrm{dL}, 705 \times 10^{\wedge} 9$ platelets/L with correct coagulation and preserved kidney function (Creatinine concentration of $0.59 \mathrm{mg} / \mathrm{dL}$ ). A Urinary analysis and a CT were performed. The result of the first one was normal, and the CT reported a myomatous uterus with a big intramural myoma of $79 \times 66 \times 77 \mathrm{~mm}$ with heterogeneous characteristics, which was already known but bigger than in the last control. These findings indicated degeneration without being able to discard infection or abscessification. It was also detected a slight dilatation of the right urinary tract caused by compression (Figures 1\&2). The study was completed by a MRI, which showed similar results (Figure 3).

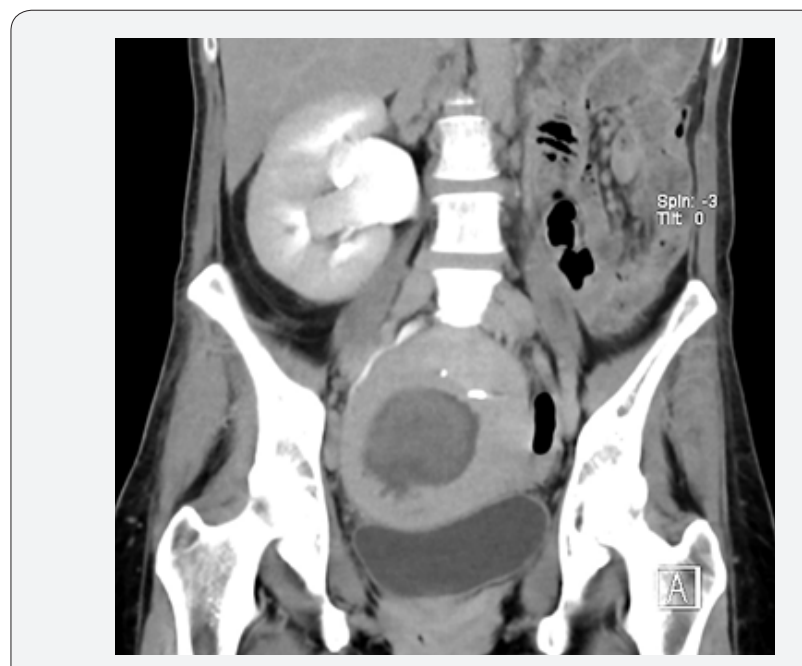

Figure 1: CT image that shows an heterogenic intramural myoma of $79 \times 66 \times 77 \mathrm{~mm}$ with the dilatation of the right urinary tract caused by compression. 


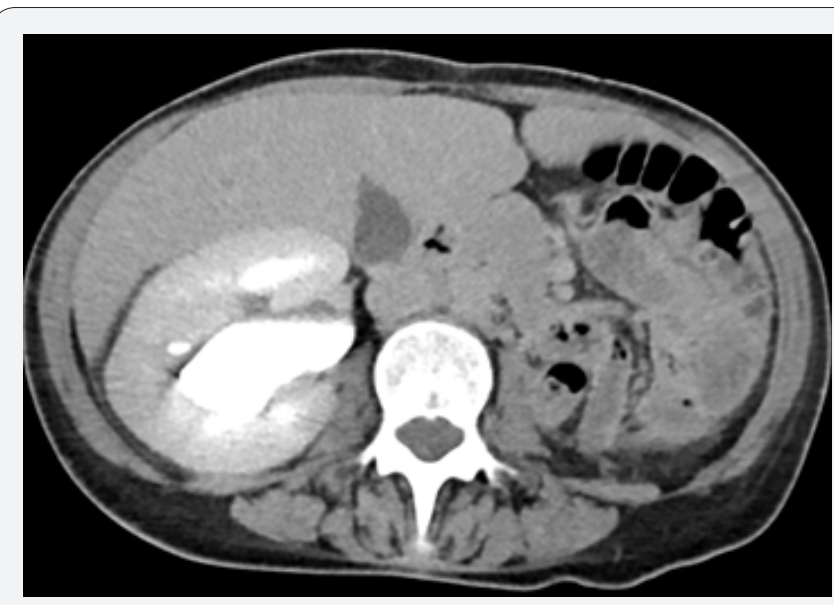

Figure 2: CT image of the dilatation of the right urinary tract caused by compression. Absence of left kidney (monorenal patient).

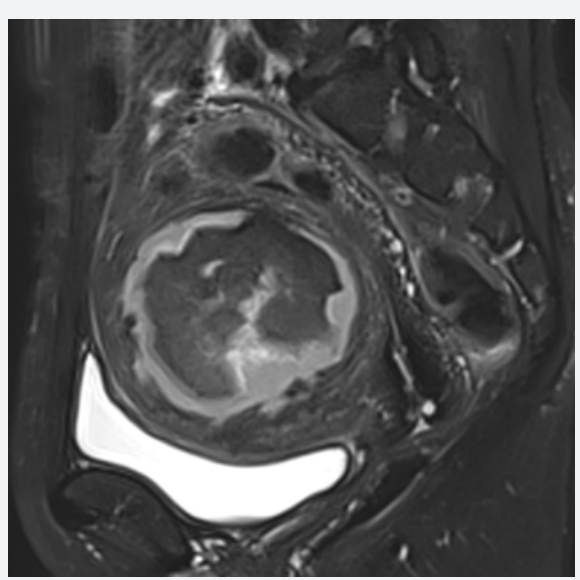

Figure 3: MRI of the intramural myoma of $79 \times 66 \times 77 \mathrm{~mm}$ with heterogeneous characteristics.

The possibility of pelvic inflammatory disease was evaluated, so endocervical and vaginal cultures were taken. Due to this clinical picture, and without being able to discard an infection of the myoma, a Fine-Needle Puncture Aspiration (PAAF) obtained abundant purulent material. Broad-spectrum antibiotic coverage was initiated and subsequently an abdominal hysterectomy with bilateral salpingectomy with previous catheterization of the right ureter (monorenal patient) was indicated.

During the surgery some purulent material from the interior of the myoma was obtained with scarce peritoneal free-liquid. Hemocultures and cultures of the material obtained were taken. After the surgery, the patient presented fast clinical and analytical improvement and could be discharged with oral treatment.

At the pre-surgery microbiological study, the endocervical culture was positive for Candida albicans and vaginal one was negative. On the other hand, the material obtained by PAAF punction and intra-surgery aspiration were positive for Bacteroides fragilis.
The macroscopic anatomo-pathlogycal study found an uterus with $1.5 \mathrm{~cm}$ thick myometrium which included multiple intramural nodular formations between 2.5 and $0.6 \mathrm{~cm}$ in diameter. In addition, the study described the presence of a $5.5 \mathrm{~cm}$ heterogeneous intramural myoma, surrounded by a cavity fulled of purulent appearance and greenish color (Figure 4). Finally, at microscopic examination, $5,5 \mathrm{~cm}$ intramural myoma with extent ischemic necrosis and high acute inflammation with focus of abscssification was described (Figure 5).
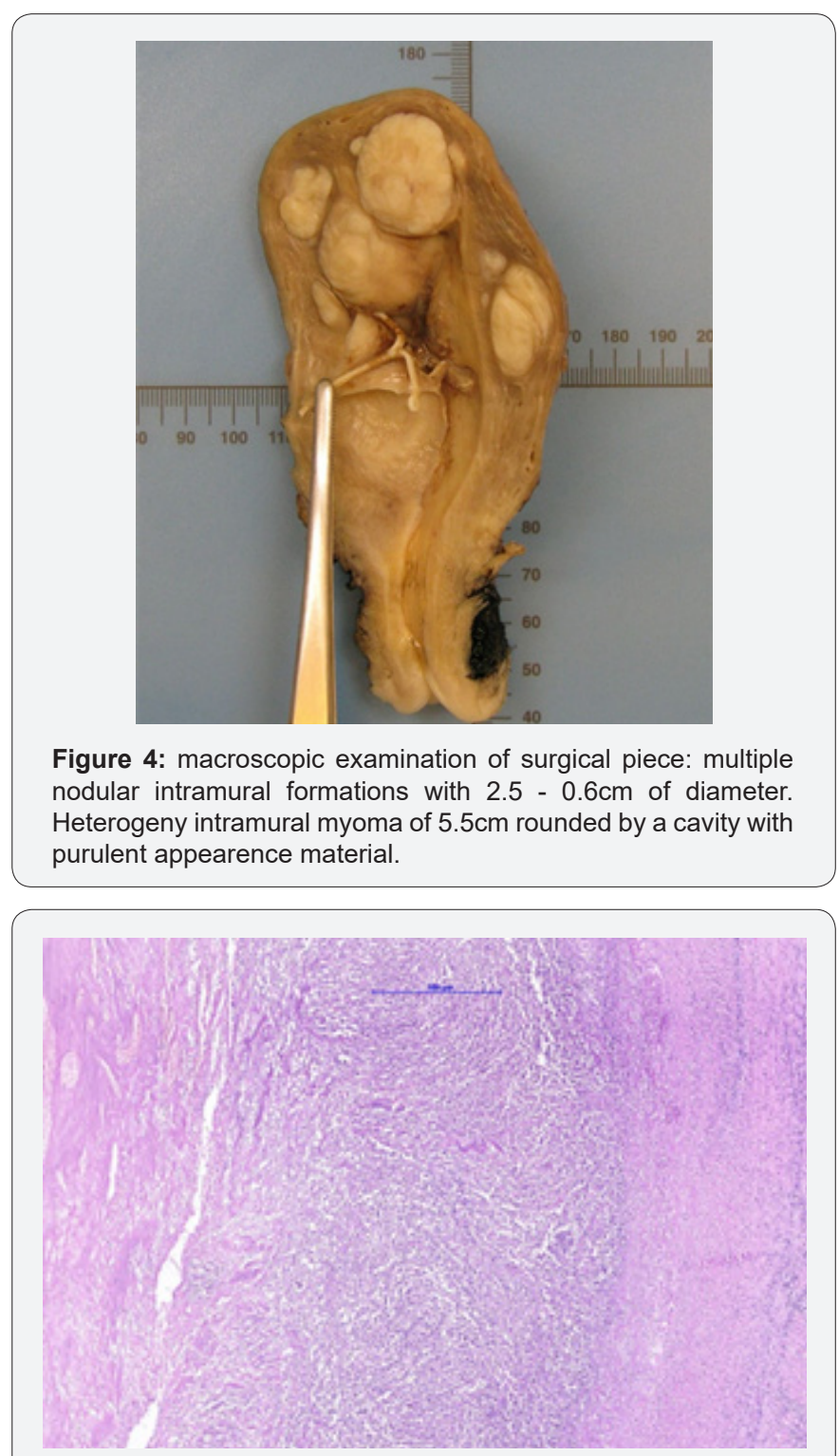

Figure 5: microscopic study of the surgical piece. Extensive ischemic necrosis and marked acute inflammation with abscess focus.

\section{Discussion}

At the moment, the prevalence of this type of diagnosis is scarce (since 1945 only 16 cases were published on the literature, and seven of them were postpartum), that is what makes our case interesting. By ultrasound examinations is very very difficult to 
distinguish between degeneration and abscecification of a myoma. Given this situation, we consider it necessary to carry out an effective and short-term treatment given the rapidity with which the condition could spread, develop a sepsis and compromise the life of the patient (it can present up to $30 \%$ mortality). In our case it was decided to initiate broad-spectrum antibiotic therapy but given the poor clinical and analytical response, we finally opted for hysterectomy. Among other treatments, drainage by aspiration-puncture, broad-spectrum intravenous antibiotic therapy in prolonged regimens or myomectomy could also be considered, individualizing the decision according to the clinical picture. Even so, currently there is not enough evidence available regarding the most appropriate treatment. We consider it would be useful to expose and study more similar cases to find the most effective solution. To face this case allowed us to consider several diagnostic possibilities and to re-evaluate comprehensively the complementary tests carried out, including them in the clinical picture of the patient until a conclusive diagnosis was reached. In addition, it led us to expand our knowledge for the early detection of similar cases to avoid possible complications.

\section{References}

1. Carballo NE, Vega AM, Guldrís NE, Vieitez VM, Cernadas PS, et al. (2010) Piomioma tras aborto de segundo trimestre de gestación. Progresos de Obstetricia y Ginecología 53(4): 159-162.

2. Stewart AE, Laughlin-Tommaso KS, Barbieri LL, Levine D, Falk JS, et al. (2017) Uterine leiomyomas (fibroids): Epidemiology, clinical features, diagnosis, and natural history. FACOG.

3. Zangeneh M, Alsadat MA, Amini E, Siadat SD, Karimian L, et al. (2010) Pyomyoma in a premenopausal woman with fever of unknown origin. Obstet Gynecol 116(2): 526-528.

4. Mubarak MY, Noordini MD (2008) A case report of pyomyoma: radiological diagnosis of a potentially fatal complication of uterine leiomyoma. The International Medical Journal 7(2): 63-65.

\section{Your next submission with Juniper Publishers will reach you the below assets}

- Quality Editorial service

- Swift Peer Review

- Reprints availability

- E-prints Service

- Manuscript Podcast for convenient understanding

- Global attainment for your research

- Manuscript accessibility in different formats ( Pdf, E-pub, Full Text, Audio)

- Unceasing customer service

Track the below URL for one-step submission https://juniperpublishers.com/online-submission.php 